Ouyang Yu. Beyond the Yellow Pale, Essays and Criticism. Melbourne: Otherland Publishing, owned by Ouyang Yu, 2010. 278 pp. ISBN: 978-0-9756092-3-1, Price: AUD 49.- Reviewed by Heide Fruth-Sachs, München

\title{
Bits and Pieces
}

This book was not love at first sight. The very small print looked dismissively unfriendly and promised tiresome reading. And much of it was. This self-published book contains a collection of thirty-one articles, essays, reflections, diary abstracts and interviews of different types and quality. Some are drafts only and should perhaps not have been published together with the more elaborate essays. Reading all this you sometimes asked yourself whether perhaps the author had felt a sudden necessity to clear his desk. Nevertheless, if you read further you find a lot of interesting information about the author, his background, his experiences as an immigrant (1991), as an Australian citizen (since 1998), as a poet, as a very sharp observer and critic of Australian culture (or non-culture, as he sees it).

\section{Disillusion}

Indeed, Ouyang $\mathrm{Yu}$ writes often aggressively and provokingly. His poem Fuck You Australia is meant to shock. The poem wants to highlight the fate of Chinese immigrants who have been repatriated. The form too is intended to irritate. The poet breaks the writing rules "australia", "china"; and even "i" have no capital letters. One understands it as a visual expression of the diminished persona of the speaker. The poem has been published in some international literary journals. However, "...no Australian scholar has cared to lend an ear to it, let alone say anything about it, treating the background as nonexistent..."(231).

Ouyang's small i can also be found in other poems. Is the Australian citizen Ouyang Yu taking it out on "the language of the Enemy"(262) through subversive spelling? The answer is: yes. He also has coined 
the metaphor "demoncrazy" for democracy intending to annoy the Australian establishment.

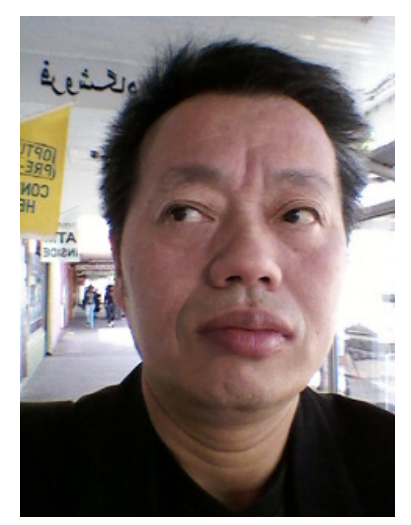

For years Ouyang Yu with his PhD in Australian and Chinese literature vainly tried to get a position in the academic world in Australia or New Zealand. He and many other intellectuals with a Chinese background who came to Australia after the Tiananmen-Square Massacre in search of freedom and democracy had to learn that they were not welcome as competitors for higher academic posts and not welcome either as authors who wanted to publish. In Ouyang Yu's opinion the reason was and always is rejection of the foreigner who is seen as a threat to the Western value system.

Similar experiences followed with publishing: Ouyang wittily calls himself a "multi-rejection author". [227.To Be(long) or Not to Be(long): Issues of Belonging in a Malticultural (another intentional misspelling) Australia, 2007] Only translation was left for him in order to make a living. He became very good at it. Quite rightly he quotes Walter Benjamin as saying "translation is the third language." Blatant irony with a sarcastic undertone is typical for many of Ouyang Yu's poems.

\section{Career Counselling to a Student of English (26)}

i know you speak good english

in fact you speak better english than most australians

i mean certainly most chinese

you can even write well

you write creatively which is fantastic

with your background

you ARE employable

as a translator and interpreter

on an on-call basis....... 


\section{Duality}

For three years (2005-2008) Ouyang held a professorship at the university of Wuhan in China. As a traveller between two worlds his ability to highlight diversities between China and Australia sharpened (for him there are very few similarities, it seems). His two languages are his life and soul. He lives them "artistically and creatively as few can", but he is still haunted by a feeling of uprootedness. He calls it "...this neither-belonging-here-nor there-ness." (126)

It does not become clear whether Ouyang Yu lost his Chinese passport by leaving China for Australia as many of his countrymen did in the 1990s. As they tried to go back they discovered that they had no longer permanent resident status in their original country. Probably Ouyang shares their fate because he fought in China against his deportation to a distant province during the Cultural Revolution, and his younger brother died as a member of the Falung Gong movement. Considering the horrors of his past, maybe, sometimes - despite everything - Ouyang is not so unhappy with his permanent resident status in Australia.

\section{Saved by poetry}

After struggling between two, even three different identities for years ("Speaking English, Thinking Chinese and Living Australian" is the subtitle of his book On the Smell of an Oily Rag, 2009, which tackles problems of translation) Ouyang Yu settled for scanning, analysing and criticising Western and Australian ways of cultural and social management. His medium is poetry, which was his companion through disappointment, depression and despair and helped him to become a recognized artist. He rejects poetry that is caculated, difficult and "upper body". In his eyes much of"... Aussie poetry targets an academic audience..." (272). Today Ouyang is a well known writer in Australia. He is invited to literary festivals, travels to Denmark, to America, to England as a respected member of his trade. He has publishers. He is a self-made man through poetry. In spite of this, Ouyang is still angry. Anger is a trademark of his. Is it a pose? Sometimes the reader of these essays cannot be sure. Ouyang points 
relentlessly at deficiencies in Australian democracy and challenges what he sees as ingrained attitudes of national arrogance. Doubtless Ouyang's persistence in becoming a recognized author must be admired. His success has been hard won.

\section{Exclusion}

Ouyang $\mathrm{Yu}$ states that there has been and still is a lot of injustice in the awarding of literary prizes in Australia. With the exception of a few Aboriginal writers, all the winners have been white authors since the foundation of the prizes. Ouyang calls the Miles Franklin Award: "a WW (white writers) preserve"(224). Some Australian-Chinese get shortlisted, but never win awards. For Ouyang

....It seems that Australia's literature equals white that equals right that equals best and the only allowance they've made is to the Indigenous people as they have to regularly cleanse their own conscience...(224)

Ouyang gives another example (Not on my Agenda, 2005) of how contemptuously Australian publishers treat the literary contributions of immigrants. In 2008 a journal of poetry with the subtitle 'Australian Issue' presented sixty-nine poets and essayists. Four were Aboriginal, "and the rest were all White...." So Ouyang concludes that

...poetry written by Australian writers of Asian, African, MiddleEastern, Southern and Eastern European and Latin American origin is not good enough, thus not fit for representing Australia in the international poetry scene and not worthy of the world's attention. (102)

Ouyang sees the reason for this exclusion in a "poetic racism - one that values the white Self over the coloured Other..."(103)

At present, Ouyang tells us, there is a trend in Australia towards Asian women writing (Jung Chun, Beth Yahp, Ang Chin Geok, Alice Pung), which is a positive development, but he regrets that "it also helps to create new stereotypes" because these books underline

what Westerners in general think a Chinese family should be like: the stone-faced Asian father figure, who beats their daughters, wives and sons... while liberation comes through the 'great white future son- inlaw.' (226) 
It is clear that Ouyang is not in favour of this trendy writing. He mentions some books by Chinese women writers that were not successful but had so much more quality: Wang Hong, Extremely Happy Parrots or Shen Zhimin, The Colourchanging Lake, which was published in Otherland.

Male Asian writers like Frank Devin, Brian Castro and Timothy Mo, or $\mathrm{Ha}$ Jin have had and still have hard times in Australia. "Australians are not interested in Chinese literature". This is "reciprocated in China where few have any interest in Australian literature..." Adds Ouyang, acid-tongued: "It serves Australian literature right"(205)

\section{Ignorance and Cultural Incorrectness}

Ouyang accuses Australian officials of not giving a damn to this very day about the correct writing of Chinese names. He interprets this practice not only as ignorance but also as an expression of contempt. "Early Chinese settlers were all losing their surnames in Australia...."(149) The result was the loss of an important part of their identity. With Chinese names the surname is always written first, followed by the given name. In Western cultures it is the other way round. In China the family names often go back thousands of years and form a rich bond of age-old family tradition. Today, says Ouyang, "Melbourne White Pages are filled with Chinese given names turned into surnames." (149) This happens also to Chinese writers in indexes or bibliographies. Mostly no Chinese name is written correctly, He found himself registered again and again as $\mathrm{Mr} \mathrm{Yu}$. It was as if one constantly referred to Shakespeare as "Mr William"(150).

Ouyang Yu also accuses Australian writers of consistently negative and stereotypical representations of Chinese and Asian characters in novels and also in scientific books. He mentions Peter Watt, Stonedragon, John Biggs, Disguises, Colleen McCullough, The Touch, and even Murray Bail, Peter Carey, Tim Winton and Shirley Hazzard are not "more enlightened or sympathetic"(63).

(59-60) Too often white authors go to China "making book, making a name but making no friends..." (67) 


\section{Don't}

Don't write me another book

In which you go to China just

To write a book or your character goes there,

for your intended purpose.....(69)

\section{Censorship}

In his essay Bonking without Book or Book without Bonking: a Personal Encounter of Cultural Censorship (2007/8;35-47) Ouyang writes about the power of Chinese editors to eliminate all passages in a book with erotic or sexual content. This happens even to translations of classical poets like John Donne. The same ban concerns disrespectful talk about superiors or politicians. The golden rule "not obscene, not pornographic, not ugly" must be obeyed.

Ouyang's opinion that a certain amount of censorship exists also in Australia, America and the UK is in a way true, but hopefully not to the same extent. Nevertheless, the example of Lao She's Camel Xiangzi, translated by Evan King as Rickshaw Boy, which became a bestseller is something to think about. Its American editor gave it a happy ending (without consulting the author) whereas the original ended sadly.

\section{English}

Ouyang Yu's statement "in many ways, English is a poor shadow of its Chinese language brother"(264) can only be a subjective view. He is at home in both languages and so are other Asian and Chinese writers in Australia. Their English may not always be up to the standard British model, but for Ouyang their English "contributes to the extension and enrichment of the English language"(107). Australian publishers see it differently. Their criterion in regard to Asian writers is still British English with its Received Pronunciation. Ouyang insists that the only criterion in judging a book should be "whether it touches the human heart and mind in a poetic way that transcends time and the boundaries of nation"(119). 